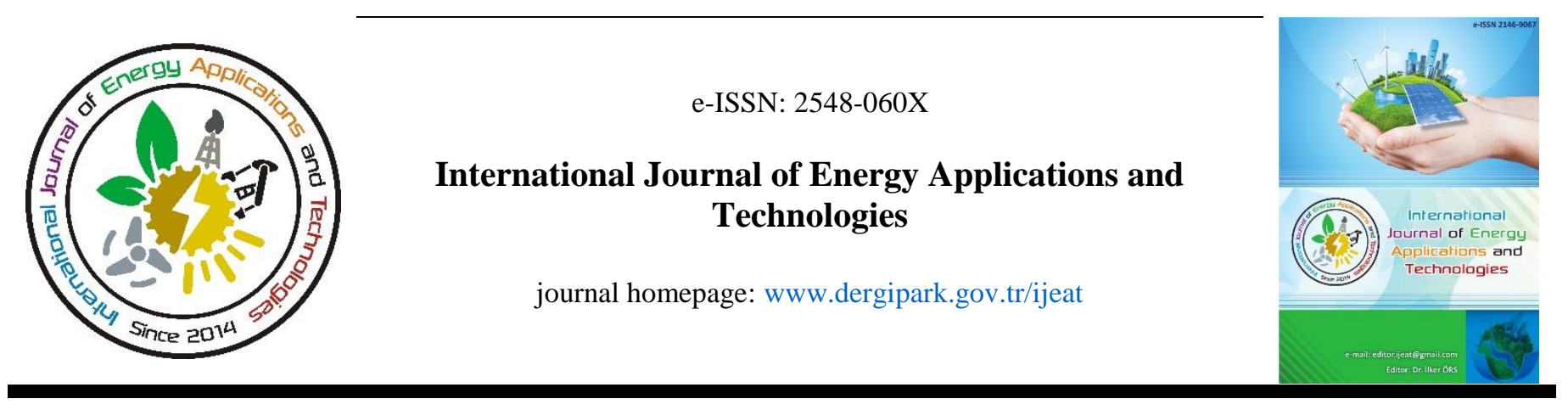

Original Research Article

\title{
The use of supercapacitor in smart metering gateway
}

\author{
Murat Şen ${ }^{*}$, Seda Üstün Ercan ${ }^{2}$, Ahmet Dalkın$^{1}$, Emrah Ayvaz ${ }^{3}$ \\ ${ }^{I}$ Electronics and Automation Department, Yeşilyurt Demir Çelik Vocational School, Ondokuz Mayls University, Samsun, Turkey \\ ${ }^{2}$ Electrical and Electronics Engineering Department, Faculty of Engineering, Ondokuz Mayls University, Samsun, Turkey \\ ${ }^{3}$ Yeşilırmak Electricity Distribution Company, Samsun, Turkey
}

\section{ARTICLE INFO \\ * Corresponding author murat.sen@omu.edu.tr \\ Received September 29, 2020 \\ Accepted March 30, 2021 \\ Published by Editorial Board Members of IJEAT \\ (C) This article is distributed by Turk Journal Park System under the CC 4.0 terms and conditions.}

doi: $10.31593 /$ ijeat. 801624

\begin{abstract}
Advanced Metering Infrastructure (AMI) consists smart meter, gateway, meter data management software. Smart meter and gateway work together to measure energy on the field. Then, gateway send the measured smart meter data that can be periodic or instant meter reading results, power factor, voltage-current-power information. In addition, gateway sends the information to the meter data management system whether there is energy or not by using a communication method in the field. If there is an integration between AMI and other distribution network systems like Outage Management System (OMS), Customer Relations Management, AMI provides measured data to these systems. Supercapacitor (SC) is a new type small energy storage device and it can easily use power system to provide the energy certain time in case of power failure. The gateway that is part of AMI connects the distribution grid physically on the field and provides own energy so when the power failure occurs in distribution grid at same time gateway energy will be cut. This means last measured data and last field situation can't be send to the AMI software so all system integration and remote meter operation will halt. This paper handles SC usage as a part of AMI system gateway on the field to provide last measured data to the AMI software. SC benefits are shown using AMI system with measured data in distribution grid. SC model will explain considering gateway design. Gateway with SC and gateway without $\mathrm{SC}$ situations will compare in terms of AMI and other system integrations.
\end{abstract}

Keywords: AMI; Gateway; OMS; Smart metering; Supercapacitor

\section{Introduction}

With the evolution of communication systems and communication infrastructures, the existing Power Grid is going through a transformation into the Smart Grid (SG), which will provide two method data communication among consumers' smart meters (SMs) and the utility company (UC) in order to collects sensitive power consumption data with the spread of smart data collection techniques and SMs [1-2]. Smart Grid applications suggest that proposes a lot of changes to the existing power grid to reduce $\mathrm{CO} 2$ emissions, ensure reliability, and manage power demands. These are especially important at the distribution level of the network where smarter applications are needed. As a result, several new applications have been made at this situation [3-4]. The advanced measurement infrastructure (AMI) is one of those applications that allows applications to measure, analyse and collect consumption data of energy, thereby adjusting power demands and prices accordingly [5-6].

AMI network, radio frequency (RF) technologies and power line communication (PLC) can be set up separately or together [6]. RF solutions - compared to PLC and other systems, require much less wiring work, thus reducing infrastructure, maintenance and deployment costs. Given that an AMI occurs of hundreds of Smart Meters, to broaden the range of an AMI solution, data transmitting elements can also be placed on poles or roofs [7]. 
Another important part of the AMI system is SC. SCs basically consist of a large number of superficial electrodes and a separating surface on an electrochemical double layer structure in which electrical energy is stored. The separating surface physically prevents contact between the electrodes, but allows ion exchange. Superficial electrodes in the structure of SC are nano-sized and increase the surface area and consequently the capacity value to very high values. SCs are widely used in many small systems. Failure of the batteries to respond quickly to fast changing loads causes the SCs to become relatively more important [8].

Moreover, rechargeable batteries generally have a life span of several thousand cycles due to the chemical reactions inside, while SCs have a very high life of up to one million cycles. One of the most important advantages of the SCs is that its work is virtually unaffected by temperature changes. SCs can work successfully even at temperatures of $-40{ }^{\circ} \mathrm{C}$, one of the worst operating conditions for batteries [9-11].

With AMI systems, the SC is located inside the gateway unit. Today, smart energy meters can record data collections, analyse storage, power outage or turn on instantaneously, but cannot actively report energy outage if power is completely off. The most important reason for this situation is that the gateway is working only when there is energy in the system so that it cannot continue reporting even when there is no energy. Therefore, there was a need for a SC capable of reporting and supplying energy within a certain period of time after cutting, even without energy. If real-time disconnection information of the line can be delivered to the main center within this period, interruption of energy can be interrupted in time and user satisfaction can be provided. It is very important that smart meters can make real-time and active reporting in case of power outage.

If the real time active reporting of power outage even is realized, timeliness of the residential power maintenance will be greatly improved, and the user satisfaction will be improved [12].

J. Gao worked on fully optimizing network architectures and communication technologies, including control on smart grid and AMI systems [13]. Alizadeh; examined the effect of optimization of production distribution in smart grid systems by applying the load statistical model [14].

\section{SC Charging Circuit}

As a capacitive element, the SC does not have discharge / charge memory that allow discharging and charging a lot of cycles without any impact over storage capacity. In addition, with equivalent series resistance (ESR), these elements can be discharged and charged at much higher rates than the best battery technologies. The absence of any current limiting mechanisms and low ESR poses a problem for the system integrator standard battery charging systems often do not work well with SC due to these components are seen as a virtual short circuit to the charging system. In order to overcome this situation, a power supply (DC) must be selected that will short circuit [15-17].

Also, passive charging network's RC time constant is often very long. Therefore, it is insufficient to charge SC with linear regulator. There are many ways to charge a SC as constant power and current charging and AC charging. In this case, constant current charging is usually preferred because this is the simplest method of charging of the excess SC. This was accomplished in two ways - diode rectifier and then return a simple converter as shown in Fig. 1 [18].

Diode bridge rectifier is applied with a rectifier. $220 \mathrm{~V} \mathrm{AC}$ wave was applied to the input of the rectifier and DC voltage was obtained between 95 and $100 \mathrm{~V}$ according to the numerical values of the circuit elements at the output. The flyback converter's input is this voltage. The converter is controlled using a microprocessor. The sensing current resistor controls the current charging of the SC, and the voltage limit is adjust to the maximum level. The SC supplies energy to the system for a certain period of time at the time of power outage, periodically, until the energy over it ends [19-20].

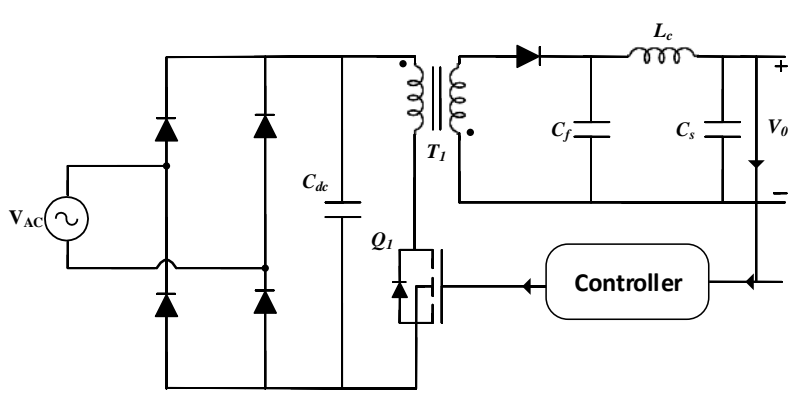

Fig. 1. SC charging circuit

\section{Using SC with Smart Metering}

\subsection{AMI system design with $\mathrm{SC}$}

The remote smart meter reading architecture of the application field is shown in Fig. 2. Smart meter, gateway, communication method and software, required in an AMI system are shown in the Fig. 2.

In the application field where the data obtained, there is a structure where the smart meter and gateway are physically separate.

The connection between the gateway and the smart meter is provided through the RS 485 communication port. With this connection of gateway and meter, smart meter configuration is completed. In some smart meter designs, it is also possible to see designs where the smart meter and the gateway are physically one piece together, which do not require an external RS 485 port connection. This communication 
method is positioned as a communication section on the gateway, and the data obtained from the meter is transferred to the main center software with this communication method. These data is processed in the main center software and then transferred to the end user interface to use in the operation. The SC positioned inside the gateway. If there is no outage in the distribution grid, SC charges itself provides energy, otherwise when a power outage occurs in the distribution grid, this time SC will provide energy to the gateway processor in order to capture power outage information in the distribution grid and send it to the AMI software. Since, SC energy supply time will change according to the size of the meter data to be sent and the frequency of transmission, the data to be sent from the field to the software should be regulated when the $\mathrm{SC}$ is activated. This regulation should be done on gateway software. Critical data such as no energy distribution grid information should be sent. Otherwise, it is possible to face the insufficiency of the energy stored by the $\mathrm{SC}$ for high volume and frequent data transmission. The figure above shows the difference between the meter reading of the field where the application is performed and the meter reading results obtained by the activation of the SC.

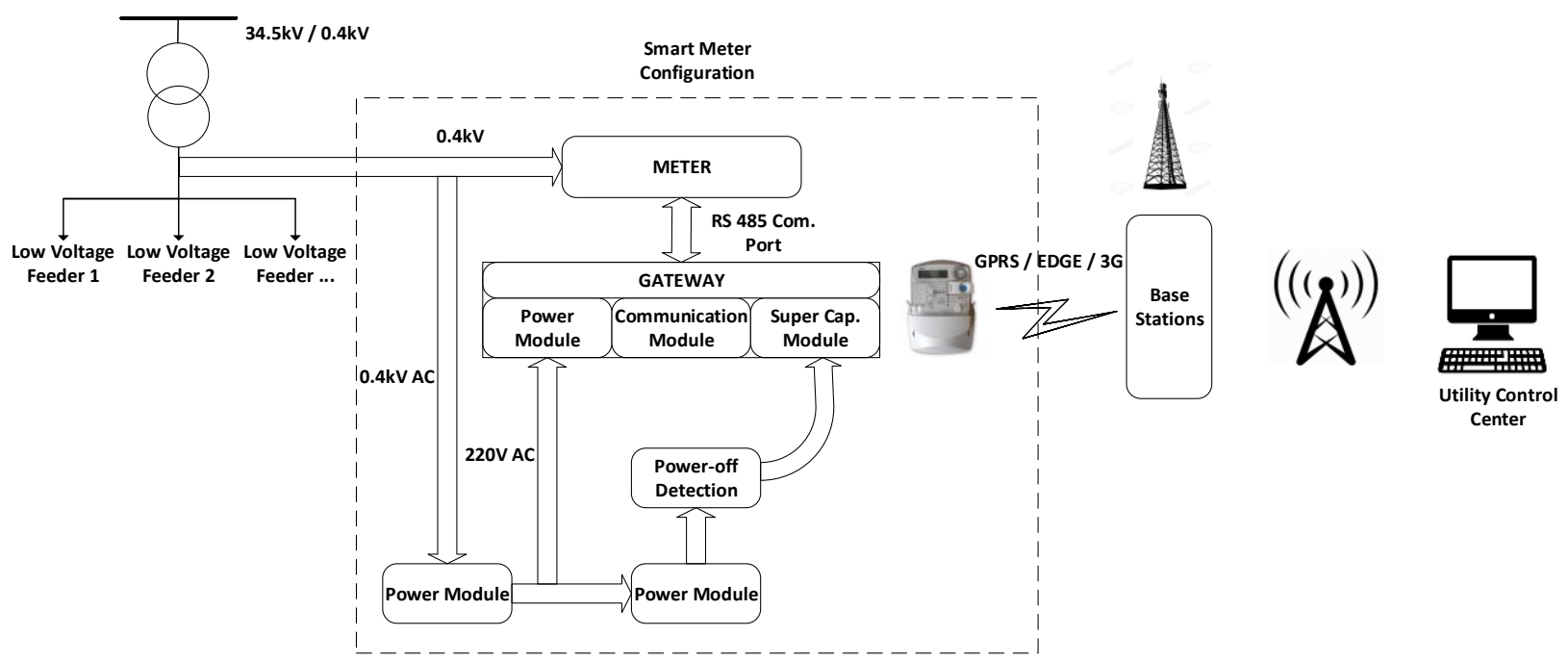

Fig. 2. AMI system design principle

\subsection{Smart metering equipment working diagram}

The design mainly focuses on solutions of the processing method and check of the smart meter and gateway for the power outage event. Smart metering equipment (meter and gateway) working flow diagram is shown in Fig. 3.

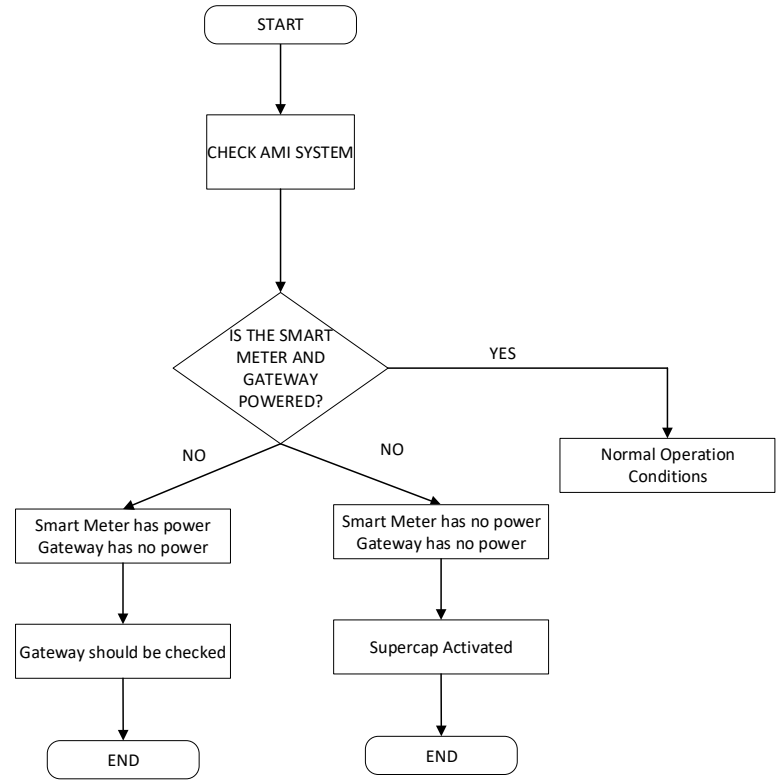

Fig. 3. Smart meter and gateway working flow chart
The system sustains normal operation if there is no power outage event. If the power is off, two different situations are encountered. Firstly, there is power in the smart meter. However, the gateway has no power. Secondly, both the smart meter and the gateway have no energy. In the first case, only a gateway-related fault occurred regardless of the system and the gateway should be checked. In the second case, the power of the all system was cut off due to any fault and SC will now be activated to send the power outage information to the AMI software.

\subsection{Comparison of supercapacitor readings with other AMI meter readings}

First of all this table was produced from Yeşilırmak Distribution Company real AMI system that is used distribution operation with SC. The situation of SCs according to other AMI smart meter readings is shown in Table 1.

Here, with the use of SC, sending only the power outage information with a smaller data, size compared to reading short and long data provided an optimum solution for user satisfaction. If larger data packets such as short and long read were sent on the SC, the energy stored by the SC would not transfer the data pack correctly, due to lack of the energy 
stored. When the meter and gateway provide input energy from distribution grid as normally, SC will only charge own self to feed the gateway during the electricity power outage. In normal operation condition, short read out and long read out will be sent to by gateway which provides input power from electricity grid.

\begin{tabular}{lccc}
\hline & SC Read-Out & $\begin{array}{c}\text { Short Read-Out } \\
\text { (without SC) }\end{array}$ & $\begin{array}{c}\text { Long Read-Out } \\
\text { (without SC) }\end{array}$ \\
\hline $\begin{array}{l}\text { Reading } \\
\text { Interval } \\
\text { Meter } \\
\text { Reading } \\
\text { Size }\end{array}$ & $\begin{array}{c}\text { Smart Meter } \\
\text { and Gateway } \\
\text { have no power }\end{array}$ & 30 minutes & 12 hours \\
& 75 byte & 1398 byte & 7729 byte \\
$\begin{array}{l}\text { Reading } \\
\text { Parameters }\end{array}$ & $\begin{array}{c}\text { Power On-Off } \\
\text { İnformation }\end{array}$ & $\begin{array}{c}\text { Pasic Meter } \\
\text { Values, Active, } \\
\text { Register }\end{array}$ & $\begin{array}{c}\text { All Meter } \\
\text { Parameters } \\
\text { (Harmonic, }\end{array}$ \\
& & $\begin{array}{c}\text { Frequences, } \\
\text { Apparent Power, } \\
\text { Cosp etc.) }\end{array}$ & $\begin{array}{c}\text { Magnetic effect } \\
\text { etc.) }\end{array}$ \\
\hline
\end{tabular}

\section{The Effect of AMI Including SC to the OMS}

Real time power outage times that occurred in any fault situation are shown in the tables. The tables was produced from the Outage Management System of Yeşilırmak Electricity Distribution Company and consist of real-time data from the field in Samsun, November 2019.

The fault of outage notification 1 with the code 401559673 occurred in the line named "Esat Çiftliği Köşk OG Fider" in Samsun Salıpazarı district. The fault of outage notification 2 with the code 401559735 occurred in the line named "Çayağzı Kök (Eski) OG Fider" in Samsun Bafra district. The fault of outage notification 3 with the code 401561500 occurred in the line named "Şeyhli Kök OG Fider" in Samsun Ladik district.

As can be seen from the tables, the first fault was resolved 6 hours 11 minutes after the power outage, second fault was resolved 58 minutes after the power outage, third fault was resolved 3 hours 50 minutes after the power outage. While
SC was passive or SC was not included to the AMI system, during this process, the fault could only be detected either by the customer calling and notifying the call center of the distribution company or by noticing the fault team on site. For this reason, there were great delays in the detection of the fault.

Yeşilırmak Distribution Company AMI system uses GPRS/EDGE/3G communication way to provide the communication between gateway and central software. In the event of a fault situation, while the smart meter and gateway are not energized, the SC transmits the power outage and the last state information to the AMI end user software or OMS thanks to integration between AMI system and OMS, at the first moment when the power is gone without waiting for any customer to call the company's call center. Thus, an opportunity occurred to send the field teams directly to that area in order to solve power outage earlier in distribution grid. When we handle first outage notification, The fault occurred at 04:49:43 but the customer called the company's call center at 08:28:19. Thanks to SC, at 04:49:43, the power outage information was notified to the center at that moment and operator chief catch a chance to send the field teams 3 hours and 39 minutes earlier to the fault area. If the customer was expected to call the company's call center, the failure situation that the operator's supervisor saw on the system at 04:49:43 was only noticed by the phone call at 08:28:19 and the teams were directed to the fault zone with a delay of 3 hours 39 minutes. Also, when looking at the real-time table, SC transmitted the information of power outage to the center again at 10:27:45.

When we handle second outage notification, the fault occurred at 08:25:17 but the customer called the company's call center at 09:10:49. Thanks to SC, at 08:25:17, the power outage information was notified to the center at that moment and operator chief get a chance to send the field teams 45 minutes earlier to the fault area.

Table 2. 401559673 Coded first outage

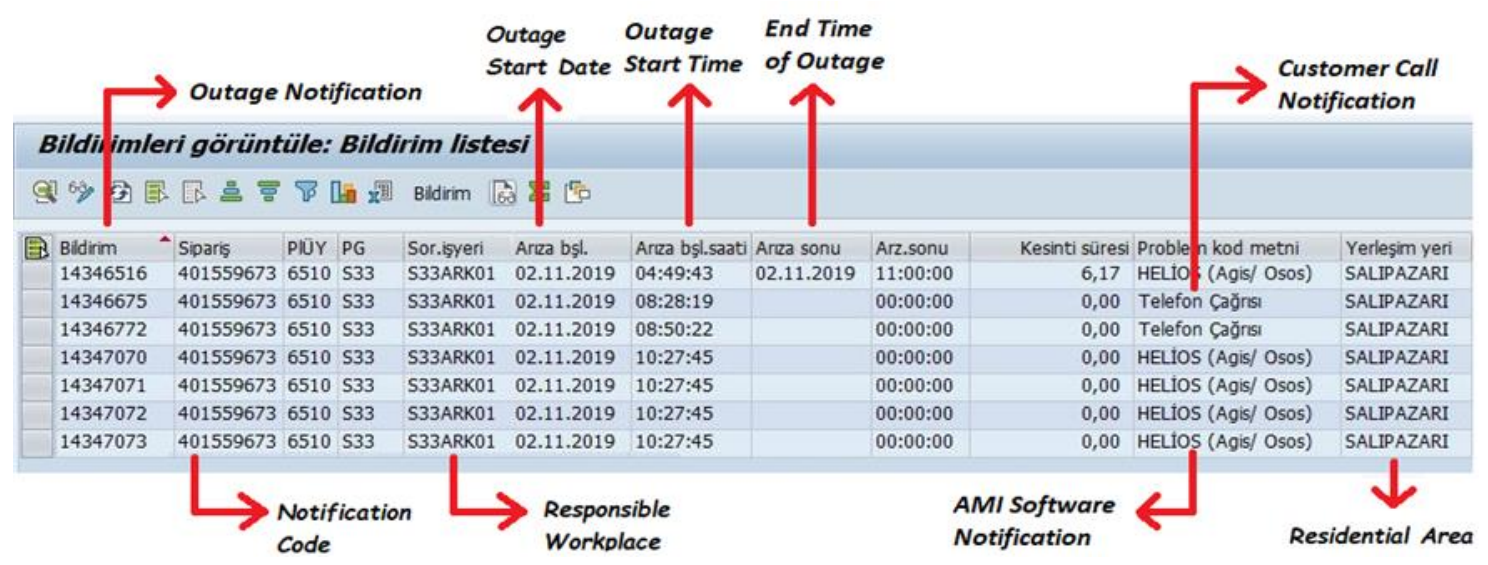


Table 3. 401559735 Coded second outage notification

\begin{tabular}{|c|c|c|c|c|c|c|c|c|c|c|c|c|c|}
\hline & & Outage & Notij & ificat & & $\begin{array}{l}\text { utage } \\
\text { tart Date }\end{array}$ & $\begin{array}{l}\text { Outage } \\
\text { Start Time }\end{array}$ & $\begin{array}{l}\text { End Tim } \\
\text { of Outas }\end{array}$ & & $\begin{array}{l}\text { II Software } \\
\text { tification }\end{array}$ & $\leqslant$ & Resid & ential Area \\
\hline & Bildi im/ & ri görünt & tüle: & Bild & irim liste & & & & & & & & \\
\hline & 368 & 回总 & 80 & $\ln 2$ & Bildrim & 60 \& & & & & & & & \\
\hline & Bildirim & Sipariş & PIOYY & PG & Sor.şyeri & Arrea bșt. & Arrza bșl.saati & Arza sonu & Arz.sonu & Kesinti süresi & i) Problem & od metni & Yerlessim yeri \\
\hline & 14346668 & 401559735 & 6510 & S11 & S11ARK01 & 02.11 .2019 & $08: 25: 17$ & & 00:00:00 & 0,00 & HELIOS ( & (gis/ Osos) & BAFRA \\
\hline & 14346669 & 401559735 & 6510 & S11 & S11ARK01 & 02.11 .2019 & $08: 25: 18$ & & $00: 00: 00$ & 0,00 & HELIOS ( & (Agis/ Osos) & BAFRA \\
\hline & 14346670 & 401559735 & 6510 & S11 & S11ARK01 & 02.11 .2019 & $08: 25: 18$ & & 00:00:00 & 0,00 & HELTOS ( & (Agis/ Osos) & BAFRA \\
\hline & 14346672 & 401559735 & 6510 & S11 & S11ARK01 & 02.11 .2019 & $08: 25: 17$ & 02.11 .2019 & 09:23:00 & 0,96 & HELIOS ( & (Agis/ Osos) & BAFRA \\
\hline & 14346677 & 401559735 & 6510 & S11 & S11ARK01 & 02.11 .2019 & $08: 29: 26$ & & 00:00:00 & 0,00 & HeLtos ( & (Agis/ Osos) & BAFRA \\
\hline & 14346678 & 401559735 & 6510 & S11 & S11ARK01 & 02.11 .2019 & $08: 29: 26$ & & 00:00:00 & 0,00 & HELTOS ( & (Agis/ Osos) & BAFRA \\
\hline & 14346679 & 401559735 & 6510 & S11 & S11ARK01 & 02.11 .2019 & $08: 29: 27$ & & 00:00:00 & 0,00 & HELIOS ( & (Agis/ Osos) & BAFRA \\
\hline & 14346680 & 401559735 & 6510 & S11 & S11ARK01 & 02.11 .2019 & $08: 29: 26$ & & 00:00:00 & 0,00 & HELIOS ( & (Agis/Osos) & BAFRA \\
\hline & 14346681 & 401559735 & 6510 & S11 & S11ARK01 & 02.11 .2019 & $08: 29: 26$ & & $00: 00: 00$ & 0,00 & HELIOS ( & (Agis/ Osos) & BAFRA \\
\hline & 14346682 & 401559735 & 6510 & S11 & S11ARK01 & 02.11 .2019 & $08: 29: 26$ & & $00: 00: 00$ & 0,00 & HELTOS ( & (Agis/ Osos) & BAFRA \\
\hline & 14346683 & 401559735 & 6510 & S11 & S11ARK01 & 02.11 .2019 & $08: 29: 25$ & & 00:00:00 & 0,00 & HELIOS ( & (Agis/ Osos) & BAFRA \\
\hline & 14346684 & 401559735 & 6510 & S11 & S11ARK01 & 02.11 .2019 & $08: 29: 26$ & & 00:00:00 & 0,00 & HELIOS ( & (Agis/ Osos) & BAFRA \\
\hline & 14346686 & 401559735 & 6510 & S11 & S11ARK01 & 02.11 .2019 & 08:30:16 & & $00: 00: 00$ & 0,00 & HELIOS ( & (Agis/ Osos) & BAFRA \\
\hline & 14346687 & 401559735 & 6510 & S11 & S11ARK01 & 02.11 .2019 & $08: 30: 16$ & & 00:00:00 & 0,00 & HELIOS ( & (Agis/ Osos) & BAFRA \\
\hline & 14346688 & 401559735 & 6510 & S11 & S11ARK01 & 02.11 .2019 & $08: 30: 16$ & & 00:00:00 & 0,00 & HELIOS ( & (Agis/ Osos) & BAFRA \\
\hline & 14346840 & 401559735 & 6510 & S11 & S11ARK01 & 02.11 .2019 & $09: 10: 49$ & & $00: 00: 00$ & 0,00 & Telefon & çağrısı & BAFRA \\
\hline
\end{tabular}

Table 4. 401561500 Coded third outage notification

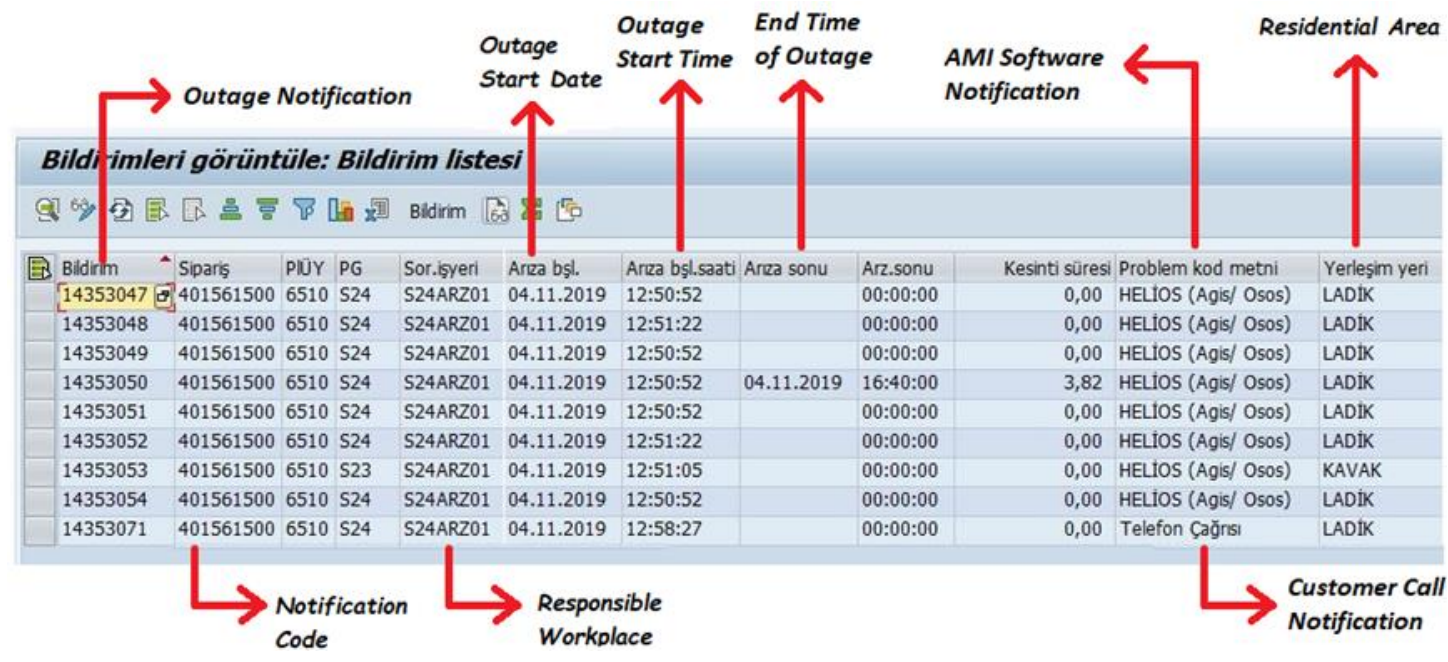

\section{YEDAŞ OMS NOTIFICATION TIMES}

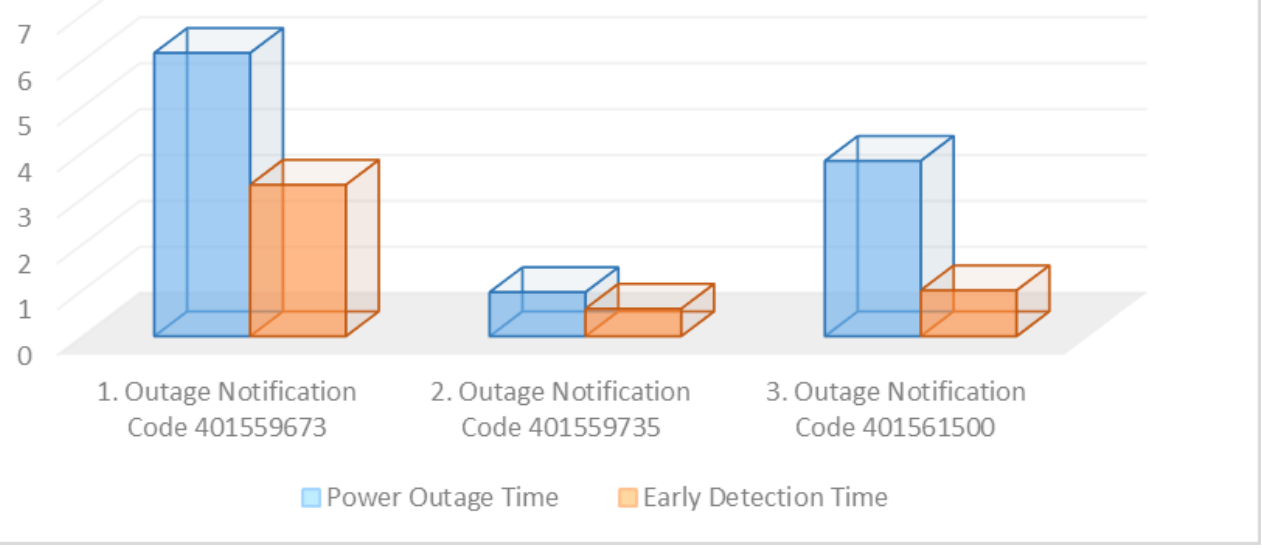

Fig. 4. Power outage and early detection time comparison 
When we handle third outage notification, the fault occurred at 12:50:52 but the customer called the company's call center at 12:58:27. Thanks to SC, at 12:50:52, the power outage information was notified to the center at that moment and operator chief catch a chance to send the field teams 58 minutes earlier to the fault area.

The data obtained from these three tables are shown in the Fig. 4. As can be seen from the Fig. 4. the response time to the faults, detected by the SC is almost half the response time determined by adhering to the customer notification

\section{Conclusions}

AMI system that includes SC was analyzed with this research. Gateway design has been introduced to use SC for smart metering. SC should send minimum data only including outage information due to its very small energy storage design for AMI. It is possible that to design SC which has big energy storage capability but this situation will not be feasible because of gateway cost and physical dimension will be higher. Gateway designs must include SC to manage distribution area efficiency. SC must send the outage information AMI software after ensure that both the gateway and the smart meter have no energy at the same time on the field. Otherwise, outage management may not be performed properly due to incorrect information. System integration should be established between distribution companies AMI and OMS. Because AMI system that is in distribution transformer low voltage distribution board has capability to detect outage of related distribution transformer. Thanks to this integration OMS can obtain this outage information from AMI system. Thus, OMS have capability to detect outage earlier even as soon as the fault occurs, if there isn't any communication problem between gateway, AMI software and OMS. This system discussed in the article is of great importance for both our daily life and the continuity of energy distribution companies. If the energy interruption information is detected early, the intervention in the system will be earlier. For this reason, both the customer is not deenergized and the energy distribution company does not exceed the yearly energy outage quota and does not pay the Ministry of Energy and Natural Resources. In conclusion, distribution companies can reduce outage time and consumers that effected the outages, so customers pleasure will provide and distributed energy will not decrease.

\section{$\underline{\text { ORCID }}$}

M. Şen

S. Üstün Ercan

A. Dalkın

E. Ayvaz
$0000-0002-8439-3862$

$0000-0002-8688-5852$

$0000-0001-5358-0297$

0000-0002-5818-7096

\section{References}

[1] Liu, C., Yang, B. and Liu, T. 2014. Efficient naming, addressing and profile services in internet-of-things sensory environments. Ad Hoc Networks, 18, 85-101.

[2] Poolo, J. 2017. A smart grid demand side management framework based on advanced metering infrastructure. American Journal of Electrical and Electronic Engineering, 5(4), 152-158.

[3] Saputro, N., Akkaya, K. and Uludag, S. 2014. A survey of routing protocols for smart grid communications. Computer Networks, 56(11), 2742-2771.

[4] Menon, D. and Radhika, N. 2015. Design of a secure architecture for last mile communication in smart grid systems. Procedia Technology, 21, 125-131.

[5] Kabalci, Y. 2016. A survey on smart metering and smart grid communication. Renewable and Sustainable Energy Reviews, 57, 302-318.

[6] Tonyali, S. 2018. "Privacy-preserving protocols for IEEE 802.11s-based smart grid advanced metering infrastructure networks". Ph.D. thesis, Florida International University, Electrical and Computer Engineering, Miami, Florida, USA.

[7] International Telecommunication Union. Working document towards a preliminary draft new report on utility communication systems, Annex 5 to Working Party 5A Chairman's Tech, AcademicPaper, Geneva, Switzerland, 2019.

[8] Erdinç, O., Uzunoğlu, M. and Vural, B. 2011. Hibrit alternatif enerji sistemlerinde kullanılan enerji depolama üniteleri. Elektrik-Elektronik ve Bilgisayar Sempozyumu, 5-7 October, Elazığ, Turkey, 116-121.

[9] Burke, A. 2000. Ultracapacitors: why, how, and where is the technology. Journal of Power Sources, 91, 37-50.

[10] Kötz, R. and Carlen, M. 1999. Principles and applications of electrochemical capacitors. Electrochimica Acta, 45(1), 2483-2498.

[11] Schindall, J. 2007. The charge of ultra capasitors. IEEE Spectrum, 4(1), 42-46.

[12] Xioang, D., Chen, Y., Chen, X., Yang, M. and Liu, X. 2018. Design of power failure event reporting system based on NB-IOT smart meter. International Conference on Power System Technology, 6-8 November, Guangzhou, China, 1770-1774.

[13] Gao, J., Xiao, Y., Liu, J., Liang, W. and Philip Chen, C. L. 2011. A survey of communication/networking in Smart Grids. Future Generation and Computer Systems, 28(2), 391-404.

[14] Alizadeh, M., Scaglione A. and Wang, Z. 2010. On the impact of SmartGrid metering infrastructure on load forecasting. Forty-Eighth Annual Allerton Conference, September 29-October 1, Illinois, USA, 1628-1636. 
[15] Chellappan, P. 2008. "Fuel cell based battery-less UPS system". Msc. thesis, Texas A\&M University, Electrical Engineering, Texas, USA.

[16] Maxwell Technologies Inc. Charging of Ultracapacitors (Document 1008981 Rev 1), 2005.

[17] Maxwell Technologies Inc. Charging ultracapacitors with current-fed power supplies (Document 009), 2006.

[18] Samosir, A. 2009. Development of a current control ultracapacitors charger based on digital signal processing. Telkomnika, 7, 145-150.

[19] Linear Technology. LT125 data sheet, California, USA

[20] Sheean, R. LT1725 Isolated flyback regulated without and optocoupler, Design Note, AcademicPaper, Linear Technology Corporation, Milpitas, USA, 2001.

ACKNOWLEDGEMENT and NOTE: This article was presented at International Conference on Advanced Technologies (ICAT'20). It was evaluated by 2 Reviewers before publish, and it has been passed all publication and evaluation processes of journal. 